\title{
INDICADORES DE QUALIDADE AMBIENTAL DA BACIA DO CÓRREGO BOM JARDIM, BRASILÂNDIA/MS
}

\author{
Nereida Vilalba Alvares de Almeida ${ }^{1}$
}

\author{
André Luiz Pinto ${ }^{2}$
}

RESUMO:Para aferir a eficiência da utilização de indicadores ambientais e avaliar a qualidade ambiental de bacias hidrográficas, utilizou-se a do Córrego Bom Jardim, Brasilândia, MS, empregando-se os indicadores fisicoquímicos da água combinados à ictiofauna, vegetação ciliar e aquática e uso e ocupação da terra. Foram monitorados em 2012, em 8 pontos, sendo capturados 185 peixes, pertencentes a 21 espécies das ordens Characiformes, Cyprinodontiformes, Perciformes e Siluriformes, e 41 espécies de macrófitas aquáticas. Os valores de pH e de CE permaneceram dentro dos limites da Resolução 357/2005 CONAMA e o OD, variou entre 1,8 e $11 \mathrm{mg} / \mathrm{L}$. Os maiores valores de turbidez e condutividade, e o menor OD foram medidos no Ponto 6, classe IV, resultante do lançamento de esgoto urbano, rala mata ciliar. Menor diversidade de peixes, sobressaindo-se os Siluriformes, cujas espécies apresentam acessórios respiratórios que permitem sobreviver em ambientes pouco oxigenados.. No Ponto 1, mata ciliar fechada, maior riqueza da ictiofauna, como Astyanax altiparanae (Characiformes), mais exigentes de OD. O Ponto 8, apesar da baixa oxigenação, rica vegetação, devido a proximidade da RPPN - Cisalpina e distante de lançamento de esgoto, com maior riqueza de macrófitas e ictiofauna, considerado berçário da Bacia e do rio Paraná. Os resultados parciais apontam que à ictiofauna e a vegetação possuem biodiversidade inferior à observada em outros bacias da região, mostrando a sua eficiência como indicador de qualidade ambiental de bacias e a necessidade de adoção de medidas para minimizar os impactos do uso, ocupação e manejo da terra nesse ecossistema.

Palavras chave: Bacia hidrográfica, Parâmetros hidrológicos, Qualidade ambiental.

\footnotetext{
${ }_{1}^{1}$ Mestrando em Geografia, UFMS/CPTL. almeidanereida@yahoo.com.br.

2 Prof.Dr.Associado III no curso de Geografia da UFMS Campus de Três Lagoas/MS andréluiz@cptl.ufms.br.
} 


\title{
INTRODUÇÃO
}

O Termo água refere-se, de modo geral ao elemento químico natural, desvinculado de qualquer uso ou utilização. Por sua vez, o termo recurso hídrico é a consideração da água como bem econômico, passível de utilização com tal fim. Entretanto, deve-se ressaltar que toda água não é, necessariamente, um recurso hídrico, na medida em que seu uso ou utilização nem sempre tem viabilidade econômica.

As atividades humanas, assim como os processos naturais, podem alterar as características físicas, químicas e biológicas da água, com ramificações especificas para a saúde humana e para os ecossistemas. A qualidade da água e afetada por mudanças em teores de nutrientes, sedimentos, temperatura, $\mathrm{pH}$, metais pesados, toxinas não metálicas, componentes orgânicos persistentes e agrotóxicos, fatores biológicos, entre muitos outros (CARR e NEARY, 2008).

\begin{abstract}
Todo tipo de uso e atividade humana exerce uma pressão sobre o meio. Porém, os diferentes usos do solo levam a diferentes graus de exposição do mesmo, favorecendo diferencialmente a incidência de processos erosivos, que carreiam o material particulado para os cursos d'água, comprometendo sua qualidade devido ao aumento da turbidez e consequentemente, desencadeando processos de assoreamento do leito (LOPES et. al., 2005).
\end{abstract}

A vantagem de se utilizar os bioindicadores é que eles permitem uma avaliação mais segura, mais confiável, da qualidade ambiental. A qualidade da água, sua composição e estado da biota aquática, encontrada no corpo hídrico, mostram as variações temporais e espaciais em função dos fatores internos e externos do mesmo (MEYBECK e HELMER, 1992).

Plantas flutuantes livres, como aguapés (Eichhornia crassipes), podem servir como meio de dispersão de filhotes de peixes que ficam em meio às raízes, ou como suporte para os ovos aderentes (DIAS et. al., 1999). Os peixes geralmente utilizam as vegetações aquáticas para se alimentar abrigar ou como locais de reprodução

Este trabalho propõe avaliar a eficiência da utilização de indicadores ambientais para avaliar a qualidade ambiental de bacias hidrográficas, utilizou-se a bacia do Córrego Bom Jardim, localizada na cidade de Brasilândia, no Mato Grosso do Sul, empregado-se os indicadores fisioquímicos de suas águas, combinados a ictiofauna e vegetação ciliar e 


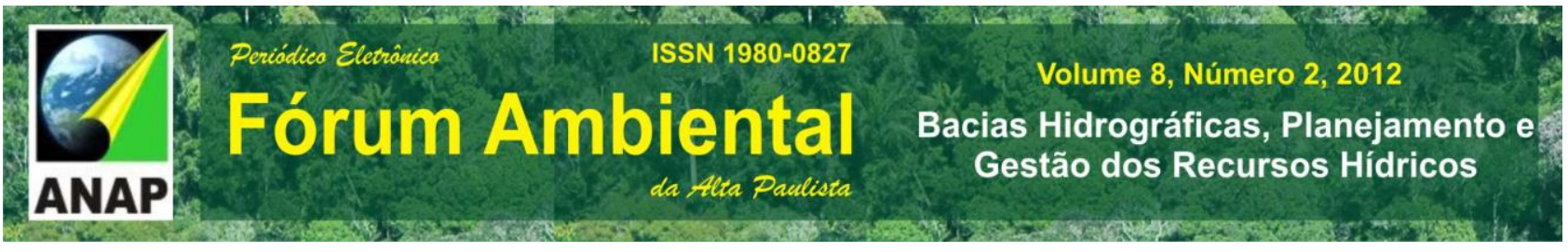

aquática, e uso e ocupação da terra da bacia. Foram monitorado estacionalmente no verão, outono e inverno de 2012, em oito pontos dispersos ao longo do canal principal e dos principais afluentes, os córregos Sete de Setembro e o Aviação.

O impacto da ocupação sócio ambiental de um território pode gerar desmatamento, degradação e perdas dos solos e da produção, além da perda da quantidade e qualidade de corpos água. Segundo ROCHA (2012) as medidas de características físicas e químicas em um ambiente são informações pontuais.

O uso dos indicadores propostos para avaliação de qualidade da água expressa diretamente as transformações socioambientais e produtivas do território, pois interagidos com as águas pluviais, fluviais e subterrâneas, refletem o grau de alteração resultante das ações humanas sobre as águas e o meio ambiente como um todo.

\section{METODOLOGIA}

Para a análise do uso, ocupação da terra e disposição da vegetação da bacia do córrego Bom Jardim foi elaborada duas cartas. A primeira produzida com base nas cartas topográficas do Departamento de Serviço Geográfico - DSG, Folhas: SF.22. V.D.I, (Brasilândia) e SF.22.V.D.II, (Dracena). As fotografias aéreas que originaram as cartas impressas em 1974 são do ano de 1966 (carta de Brasilândia) e do ano de 1965 (carta de Dracena) ambas na escala 1: 60.000. Utilizou-se o ano de impressão como ano de referência na carta de uso, ocupação da terra e disposição da cobertura vegetal da bacia. As cartas foram digitalizadas e trabalhadas em ambiente do software AutoCAD 2008. A segunda carta foi construída com base na imagem de satélite Landsat 5_TM de agosto de 2009, órbita: 223 - ponto: 75, trabalhadas inicialmente no software Spring 5.1.6, e posteriormente finalizada no Auto CAD-2008, utilizando quando relevante, as informações das cartas topográficas..

Monitorou-se a qualidade das águas superficiais da microbacia do córrego Bom Jardim, utilizando-se do oxigênio dissolvido e dos parâmetros coadjuvantes de turbidez, $\mathrm{pH}$ e condutividade elétrica, em oito pontos ao longo do córrego e, para as estações dos anos de 2009, 2010, 2011 e 2012. Para a análise dos parâmetros e verificação da qualidade das águas superficiais do Córrego Bom Jardim foi empregado os equipamentos 
e métodos relacionados no Quadro 1. Com os resultados dos parâmetros medidos, pôdese fazer o enquadramento dos pontos analisados nas classes de água expressas pelas resoluções 357/2005 e 430/2011 do Conselho Nacional do Meio Ambiente - CONAMA.

Quadro 1: Parâmetros, Equipamentos e Métodos Utilizados para Análise da Qualidade das Águas Superficiais do Córrego Bom Jardim, no Município de Brasilândia/MS

\begin{tabular}{|l|l|l|}
\hline \multicolumn{1}{|c|}{ Parâmetros } & Equipamentos & \multicolumn{1}{c|}{ Método } \\
\hline Oxigênio Dissolvido OD & Lutron DO - 5510 & Espectrofotométrico \\
\hline Condutividade & Tecnopon MCA - 150 & Eletrométrico \\
\hline Turbidez & Tecnopon TB 1000 & Eletrométrico \\
\hline $\mathrm{Ph}$ & Phtek $\mathrm{pH}-100$ & Eletrométrico \\
\hline Temperatura & Lutron DO -5510 & Eletrométrico \\
\hline
\end{tabular}

O oxigênio dissolvido nas águas naturais, o oxigênio é indispensável também para outros seres vivos, especialmente os peixes, onde a maioria das espécies não resiste a concentrações de oxigênio dissolvido na água inferiores a 4,0 mg/L. É, um parâmetro de extrema relevância na legislação de classificação das águas naturais, bem como na composição de índices de qualidade de águas (IQAs).

A condutividade expressa à capacidade de condução de corrente elétrica de sais dissolvidos e ionizados presentes numa água, deve ser utilizada como parâmetro de avaliação de qualidade.

A turbidez é a alteração da penetração da luz provocada por partículas em suspensão, como bactérias, argilas e silte ou fontes de poluição que lançam materiais finos e outras substâncias na água. A presença dessas substâncias provoca a dispersão e a absorção da luz, dando à água aparência nebulosa, esteticamente indesejável e potencialmente perigosa (PINTO, 1998).

$\mathrm{O}$ pH apresenta a acidez ou a basicidade das águas, que podem ter origens em fatores naturais do terreno ou resultantes de poluentes dissolvidos na água. $A$ analise do $\mathrm{pH}$ foi efetuada através do método eletrométrico (CETESB, 1987).

A temperatura do ar e da água influencia nos processos biológicos, reações químicas e bioquímicas que ocorrem na água e também outros processos como 
solubilidade dos gases dissolvidos, além de acentuar a sensação de sabor e odor (PINTO, 1998).

Para a caracterização florística foram coletadas amostras da vegetação marginal e aquática para em laboratório, com uso de chaves de identificações específicas (POTT e POTT, 2000) são identificados, prensados e disponibilizados como testemunho no Herbário da Universidade Federal de Mato Grosso do Sul, Campus de Três Lagoas CPTL. Na amostragem para ictiologia foram utilizados os seguintes apetrechos: Redes de emalhar com malhas de 15, 30 e $40 \mathrm{~mm}$ medidos entre nós opostos, que possuem $10 \mathrm{~m}$ de comprimento e altura média $1,20 \mathrm{~m}$, rede de arrasto $20 \mathrm{~m}$ comprimento e malha de 2,5 $\mathrm{mm}$; peneirão quadrado de $1 \times 1 \mathrm{~m}$ e malha de $2,5 \mathrm{~mm}$.

Nos pontos monitorados foram feitas as coletas de água e realizados arrastos visando à captura de espécies de pequeno porte; ao final do trabalho foram armadas 03 redes, permanecendo na água por aproximadamente umas 15 horas, para captura de peixes maiores. Todos os peixes capturados são acondicionados em sacos plásticos, separados por ponto de coleta e artefato de pesca, fixados em formalina a 10\%. Em laboratório foi realizado a análise da turbidez da água e, após a triagem das amostras, identificados os exemplares de peixes. Os peixes capturados foram colocados e recipientes com álcool 70\%, para sua conservação e disponibilização, no depósito de testemunho do Laboratório de Ictiologia da Universidade Federal de Mato Grosso do Sul, Campus de Três Lagoas - CPTL.

A identificação das espécies (peixes) baseou-se nas chaves de identificação de GRAÇA e PAVANELI (2007) e BRITSKli et. al. (1999). Quando não identificados no laboratório de ictiofauna do CPTL, mesmo com auxilio das bibliografias existentes, estes foram enviados para outros laboratórios especializados, tais como da USP, UEM, entre outros.

Após a elaboração do mapa base, na escala de 1:100.000, que engloba a rede de drenagem, estradas e o centro urbano. Selecionaram-se oito pontos ao longo do canal principal e dos principais afluentes da bacia do córrego Bom Jardim, os córregos Sete de Setembro, no alto curso e o córrego Aviação, no médio curso, para que suas águas, peixes e vegetação aquática, fossem monitorados, no verão, outono e inverno de 2012. 


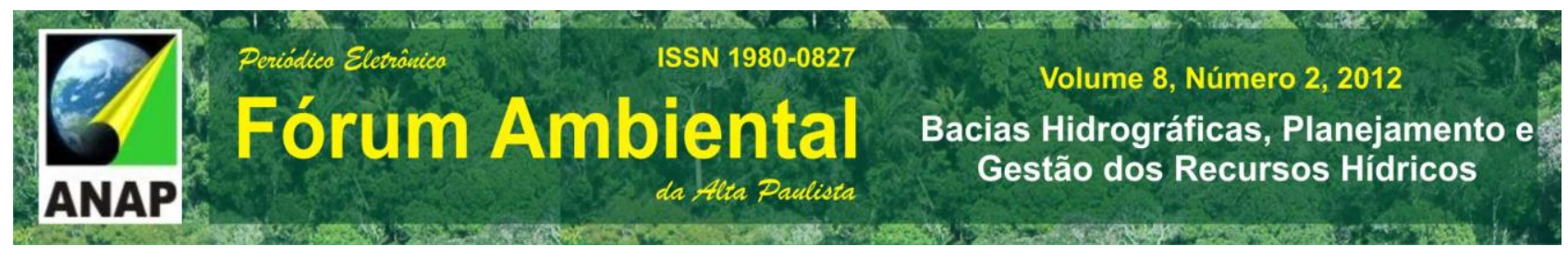

Para a seleção dos pontos foi levando em consideração, as confluências dos tributários e a diversidade de uso, ocupação e manejo da terra (Figura 1).

Ponto (1); localiza-se no canal principal do Bom Jardim, em mata ciliar fechada, que se entrelaça a área de cerrado conservado da reserva legal da Fazenda Capela 3Araraquara, (2) Fazenda Alvorada II, Bom Jardim a montante do Sete de Setembro, (3) Fazenda Alvorada II, no córrego Sete de Setembro, (4) Fazenda Alvorada II, no Bom Jardim a jusante do Sete de Setembro, (5) Fazenda Almeida, a montante do Córrego Aviação, (6) Fazenda Almeida, no córrego Aviação, (7) Fazenda Almeida, a jusante do Córrego Aviação e (8) no inicio da RPPN Cisalpina.

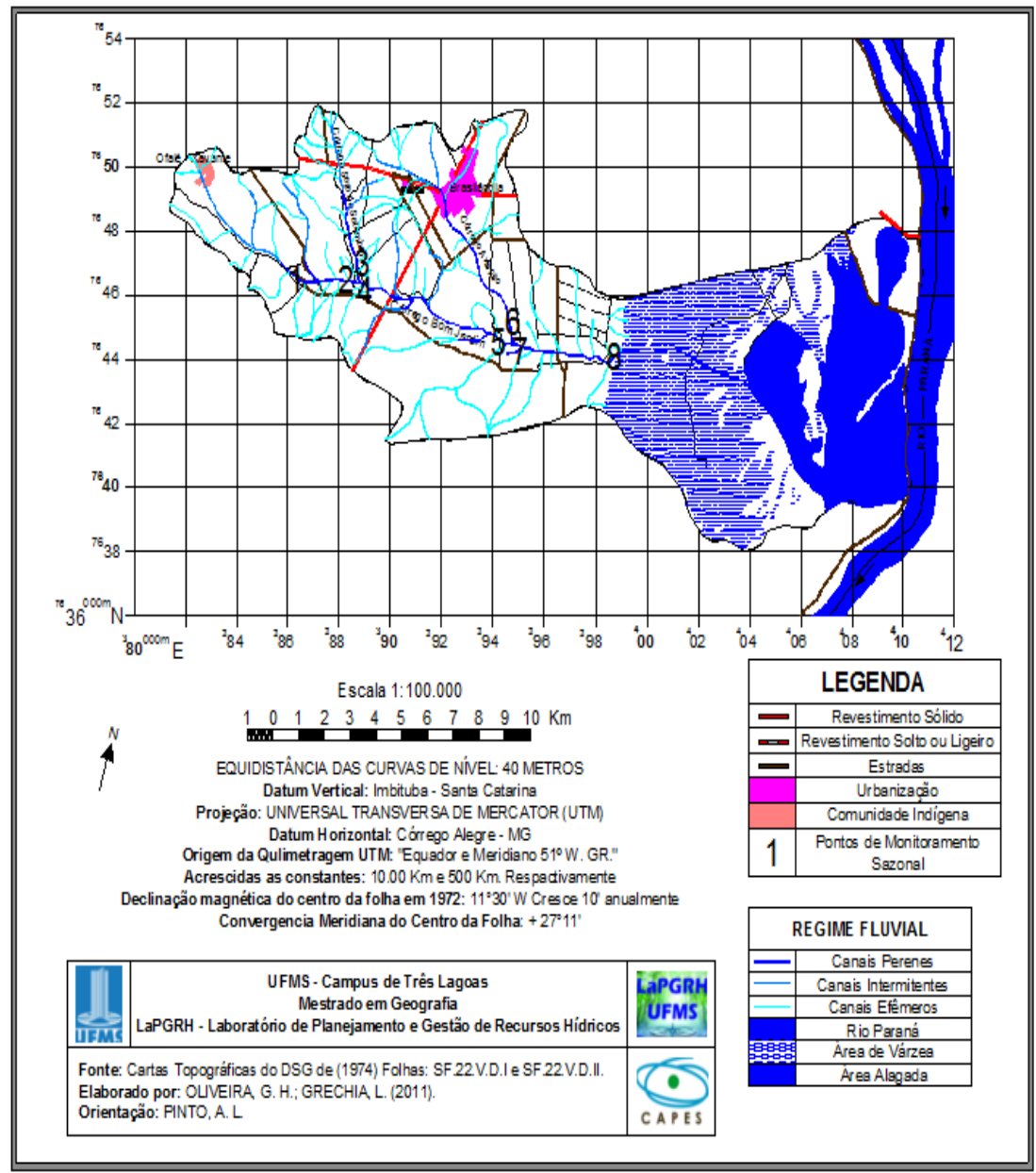

Figura 1: Localização pontos de monitoramento da qualidade das águas superficiais, ictiofauna e vegetação aquática da bacia do córrego Bom Jardim, Brasilândia/MS.

VIII Fórum Ambiental da Alta Paulista, v. 8, n.2, 2012, p. 118-129. 


\section{DISCUSSÃO E RESULTADOS}

Em 1966, a cobertura vegetal nativa ocupava $74,54 \%$ da área da bacia, a pastagem 22,93\% e a agricultura em larga escala não existiam (Figura 2).

Em 2009 a cobertura vegetal primitiva possui apenas 37,3\%, mesmo levando-se em consideração as área da aldéia indigena Ofayés Xavante e a Reserva do Patrimônio Particular Natural -RPPN Cisalpina. Em compensação as pastagem foram 36,63\% da área da bacia, Figura 3.

Comparando os resultados obtidos em 1966 e 2009, foram constatadas diversas alterações na bacia do córrego Bom Jardim que ocorreram devido aos diferentes tipos de uso do solo ao longo desses 37 anos (Quadro 2).

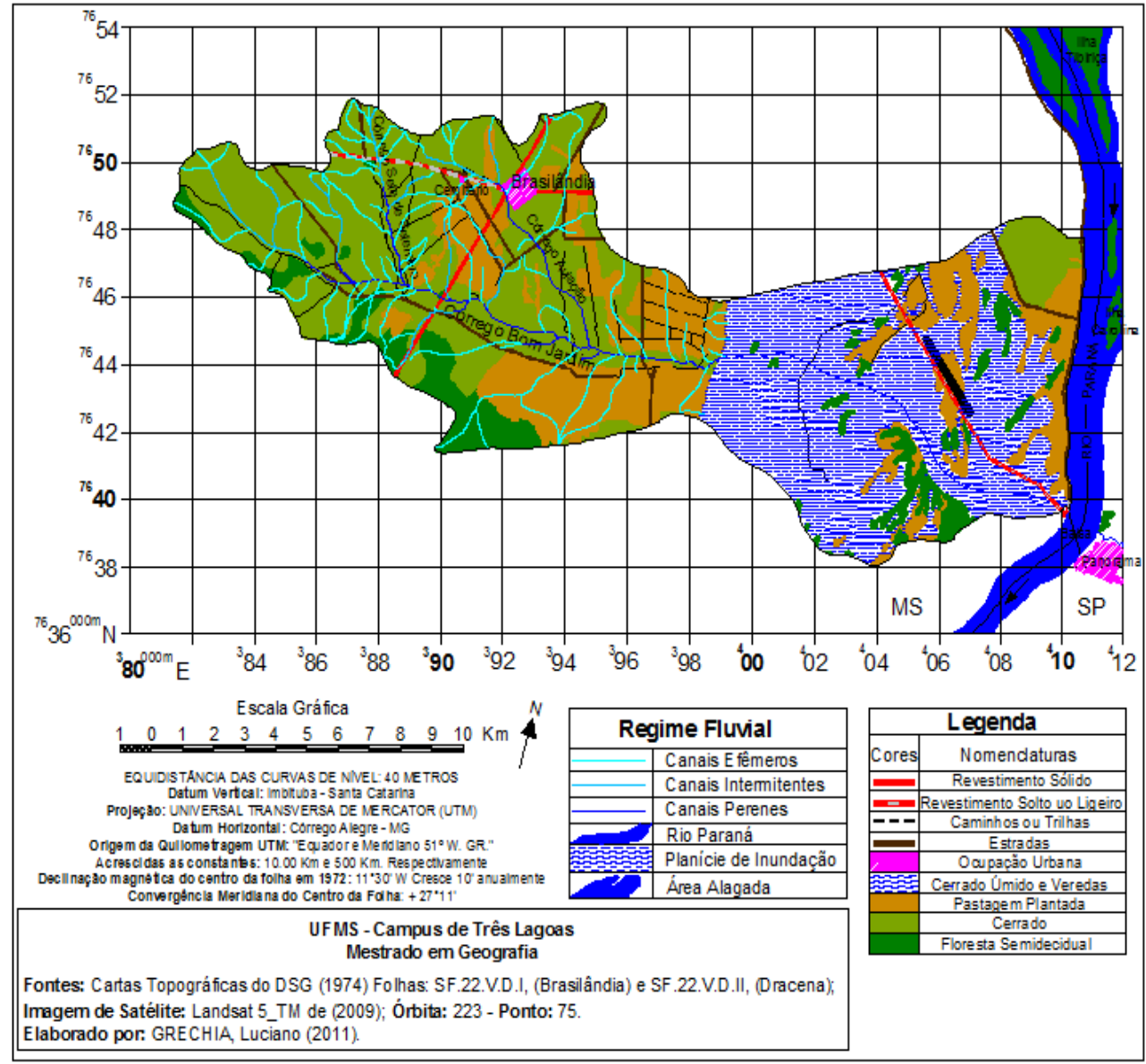

Figura 2. Carta de uso e ocupação da terra e distribuição da vegetação da bacia do córrego Bom Jardim, Três Lagoas/MS, em 1966. 

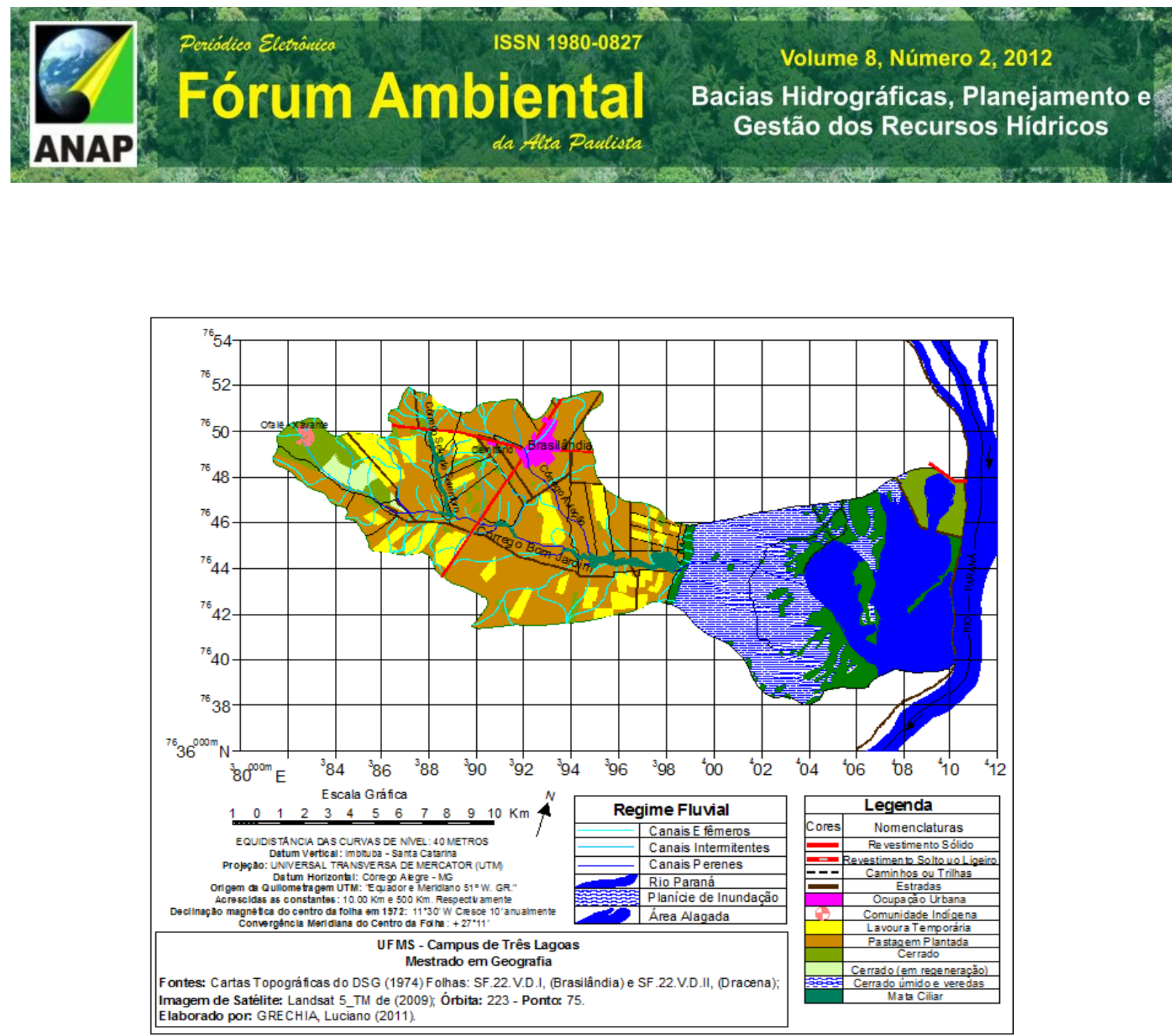

Figura 3. Carta de uso e ocupação da terra e distribuição da vegetação da bacia do córrego Bom Jardim, Três Lagoas/MS, em 2009.

Quadro 2 - Evolução de uso e ocupação da terra, entre 1966 e 2009, e alterações na bacia hidrográfica do córrego Bom Jardim, Brasilândia/MS.

\begin{tabular}{|c|c|c|c|c|c|c|}
\hline \multirow{2}{*}{$\begin{array}{l}\text { Classes de Uso e } \\
\text { Ocupação do Solo }\end{array}$} & \multicolumn{2}{|c|}{1966} & \multicolumn{2}{|c|}{2009} & \multicolumn{2}{|c|}{ Alteração } \\
\hline & Área $\left(\mathrm{km}^{2}\right)$ & $\%)$ & Área $\left(\mathrm{km}^{2}\right)$ & (\%) & $\begin{array}{l}\text { Area } \\
\left(\mathrm{km}^{2}\right)\end{array}$ & (\%) \\
\hline Rodovias e estradas & 4,179 & , 14 & 4,819 & 2,35 & $-0,640$ & $-0,21$ \\
\hline Cidade & 0,762 & ,39 & 2,060 & 1,04 & 1,298 & 0,64 \\
\hline Lavoura temporária & 0,000 &, 00 & 14,858 & 7,51 & 14,858 & 7,51 \\
\hline Pastagem plantada & 44,699 & 2,93 & 72,719 & 36,63 & 28,020 & 13,70 \\
\hline Cerrado & 69,729 & 5,79 & 11,566 & 5,82 & 58,163 & $-29,97$ \\
\hline Cerrado (em regeneração) & 0,000 & ,000 & 2,374 & 1,10 & 2,374 & 1,10 \\
\hline Cerrado úmido e veredas & 59,321 & 0,45 & 38,285 & 19,52 & 21,036 & 10,93 \\
\hline
\end{tabular}




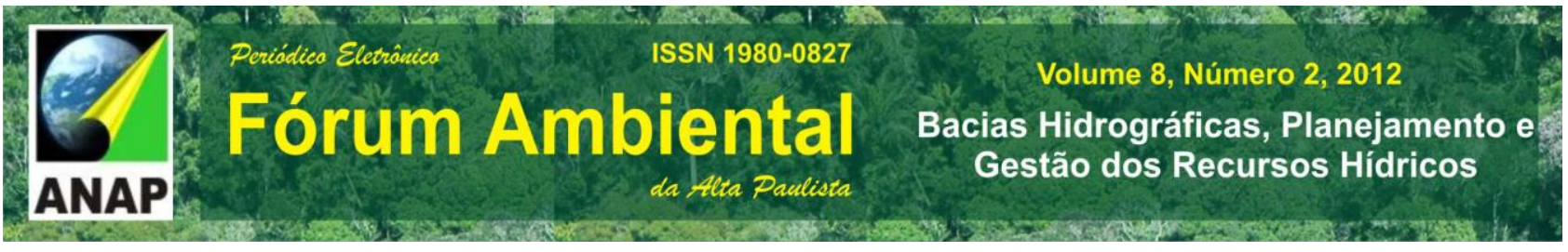

\begin{tabular}{|c|c|c|c|c|c|c|}
\hline Floresta Semidecidual & 16,176 & ,30 & 16,213 & 9,73 & 0,037 & 1,43 \\
\hline Mata ciliar & $--^{*}$ & $-{ }^{*}$ & 2,411 & 1,13 & $--^{*}$ & $--^{*}$ \\
\hline TOTAL & 194,866 & 00 & 194,866 & 100 & 126,426 & 64,87 \\
\hline Terra Indígena & -- & - & 7,760 & 3,98 & -- & -- \\
\hline Área Agricultável & -- & - & 98.398 & 50,49 & -- & -- \\
\hline RPPN - Cisalpina & -- & - & 88,708 & 45,52 & -- & -- \\
\hline Área alagada na Reserva & -- & - & 29,561 & 15,17 & -- & -- \\
\hline
\end{tabular}

* informações diluídas entre outras vegetações

Fonte: GRECHIA (2011).

A vegetação nativa da área vista na carta de 1966 cedeu lugar a pastagens plantadas e as lavouras temporárias, na carta de 2009, foram reduzidas em 420,878km². Em 2009 aparecem 2,374Km² de cerrado em regeneração e as áreas recobertas por cerrado úmido e veredas sofreu alagamento numa área de $29,561 \mathrm{Km}^{2}$. A vegetação semidecidual sofreu pouca alteração de 1966 para 2009, porém, essa atualmente só é vista na reserva Cisalpina, não estando presente na área agricultável.

As culturas temporárias, em 2009, devem-se não somente ao aumento da população do município neste período, mas também à criação do assentamento Pedra Bonita destinada a famílias de ribeirinhos, após a construção da U.H.E. Sergio Motta, pela CESP, além do crescimento da área recoberta pela malha urbana, que quase triplicou de tamanho passando de 0,762km² em 1974 para 2,060 Km² em 2009.

Da ictiofauna, foram coletados 185 indivíduos nas ordens Characiformes, Cyprinodontiformes, Perciformes e Siluriformes. Entre as espécies mais abundantes, destacam-se Serrapinnus sp. (tipo de lambari), Cichlidae (carazinho), Serrapinnus notomelas (lambarizinho), Hyphessobrycon moniliger (lambarizinho), Moenklausia aff. gracilima etc.

As vegetações aquáticas foram coletadas e identificadas em 41 espécies, dentre aquáticas e vegetação de borda entre elas: Limnocharis flava, Ottelia brasiliensis etc..

Os parâmetros de análise da qualidade da água foram comparados nos anos de 2009 a 2012 índices de pH permaneceram entre 6,6 a 7,9 nos anos de 2009 a 2012, 
dentro dos limites do enquadramento do CONAMA, para a classe especial, a turbidez foi de 1,54 a 276 NTU, essa concentração ocorreu no ponto 6 no verão de 2010, sendo enquadrado na classe IV do CONAMA, condutividade elétrica teve variação de 2,00 a 65,00 ums, esse índice foi obtido no ponto 6, também no verão, só que de 2012. Oxigênio dissolvido obteve grande variação ao longo desses quatro anos de 11,00 a 1,8 mg/l, essa concentração muito baixa, também ocorreu no ponto 6 , no verão de 2012 , a enquadradoa na classe IV.

Dentre esses pontos três tiveram índices relevantes para nossa comparação ponto 1 com vegetação aquática, mata ciliar e reserva legal, presença de ictiofauna diversificada dentre eles o Serrapinnus, espécie considerada exigente, na qualidade ambiental de seu habitat, sendo geralmente encontrados, em ambientes preservados. Ponto 6 recebendo as águas residuárias da cidade tratadas por uma ETE, em todas as estações do ano monitoradas, obteve baixo concentração de oxigênio e apenas uma vegetação que sobrevive nesse ambiente extremamente degradado, a espécie Persicaria ferruginea.. Neste ponto foram encontradas apenas três espécies de peixes (Siluriformes). Sendo que essas espécies de peixe consegue sobreviver em águas pouco oxigenadas, por possuir um tipo de respiração acessória.

O ponto 8 obteve aumento de espécies capturadas, apesar de baixa concentração de oxigênio dissolvido em suas águas, no outono de 2012 provavelmente por ter animais pastando dentro do canal fluvial, aumentando a quantidade de nutrientes. Bem como, por limitar-se com a RPPN Cisalpina, que consciente em grande berçário para a ictiofauna desse trecho do rio Paraná, onde o Bom Jardim tem sua foz.

\section{CONCLUSÃO}

Esses resultados da pesquisa apontam a fragilidade na subbacia do córrego Aviação (ponto 6), praticamente sem proteção das matas ciliares, recebe efluentes da estação de tratamento de esgoto da cidade de Brasilândia e de ligações clandestinas de esgoto nas galerias pluviais e não consegue diluir e nem assimilar esses poluentes. enquadrando-o na classe IV do CONAMA, que limita o uso de sua água para fins paisagísticos, reflete na pobre de sua ictiofauna e vegetação aquática. O córrego Sete de 
Setembro (ponto 2), também esta sofrendo forte desmatamento, que consequentemente reduz a qualidade de suas águas e a quantidade de espécies de peixes e de vegetação aquática.

Enquanto que, nos pontos 1 e 8 , devido à proteção das matas ciliares e das reservas legais, em especial de cerrado, possuem grande diversidade de espécies de peixes e vegetação aquática. Concluindo-se que, as proteções das matas ciliares e das reservas legais são fundamentais para a manutenção da qualidade das águas e da biodiversidade da flora e fauna aquática.

Portanto, esses indicadores mostraram-se muito eficientes para a avaliação da qualidade ambiental de bacias hidrográficas, pois bem retratam o nível de conservação ambiental, sendo instrumentos eficazes para planejar e gerir ambientes hídricos.

Propõem-se que o Ministério Publico, IMASUL e a Secretaria Municipal de Meio Ambiente, promova com urgência o recomposição das matas ciliares da bacia, bem como a necessidade da utilização de praticas agrícolas de conservação da terra e que fiscalize proprietários que desrespeite a legislação ambiental, visando a sustentabilidade da bacia.

\section{REFERENCIAS}

BRASIL Conselho Nacional do Meio Ambiente - CONAMA Resolução 357/2005, Enquadramento do Corpos Hídricos Superficiais no Brasil.. Governo Federal, Brasilia. Publicada no DOU n 53, de 18 de março de 2005, Seção 1, páginas 58-63.

BRITSKI, H.A. ; SILIMON, K.Z.; LOPES, B. S. Peixes do Pantanal . Manual de Identificação. Embrapa Brasília - SPI e Corumbá - CPAP. Brasília, 1999: 184p.

CARR, G.M. and J.P. NEARY. Water Quality for Ecosystem and Human Health, 2nd Edition. United Nations Environment Programme Global Environment Monitoring System. Retrieved 14 July 2009, from http://www.gemswater.org/publications/ pdfs/water_quality_human_health.pdf., 2008. 
CETESB. Companhia de Tecnologia de Saneamento Básico. Guia de coleta e preservação de amostras de água. São Paulo, 1987: 150 p. (Séries guias)

DIAS, E. S.; POTT, V. J.; HORA, R.C da.; SOUZA, P. R. Nos jardins submersos da Bodoquena: guia para identificação de plantas aquáticas de Bonito e região- Campo Grande , MS : Ed. UFMS, 1999. 160p.

GRAÇA,W.J. ;PAVANELLI, C.S.. Peixes da Planicie de Inundação do Alto Rio Paraná e Áreas Adjacentes. Maringá: EDUEM. 2007

GRECHIA, L. Dinâmica Morfológica da Bacia Hidrográfica do Córrego Bom Jardim, Brasilândia, MS. 2011. (Dissertação Mestrado em Geografia) - Universidade Federal de Mato Grosso do Sul, Campus de Três Lagoas.2011

LOPES, F. W. A.; PEREIRA, J. A. A.; ANDRETTA, V.; VITTORINO, M. R., 2005, Análise da qualidade da água, Degradação Ambiental e Atividade Turística no entorno da Cachoeira da Fumaça, Carrancas- MG. In: Simpósio Brasileiro de Geografia Física Aplicada, 11, 2005, São Paulo. [Anais...] São Paulo: USP. p. 4855-4862.

MEYBECK M.; HELMER R.; DRAY M.; EL GHOBARY H.; DEMAYO A.; RAMADAN S.;KHAN K.; PETERSON P.; JACKSON J. 1991. Water quality, progress in the implementation of the Mar del Plata Action Plan. WHO/UNEP. 79p. (UN Conference on Water, Dublin, 1992).

SILVA,,C.P.D., 1995. Community Structure of fish in urban and natural in the Central Amazon. Amazoniana. XII (3/4): 221.236

PINTO, A. L. Saneamento Básico e suas Implicações na Qualidade das Águas Subterrâneas da Cidade de Anastácio (MS). 1998. 175 p. Tese (Doutorado e Geociências) - Universidade Estadual Paulista/Instituto de Geociências e Ciências Exatas, Rio Claro, 1998.

ROCHA, O. Entrevista ao Clik Ciência. 2012, disponível em (http://www.clickciencia.ufscar.br/portal/edição17/entrevista print.php) acesso em 11/08/2012. 